\title{
Advances in Optical Coherence Tomography and Confocal Laser Endomicroscopy in Pulmonary Diseases
}

\author{
Annika Goorsenberg Kirsten A. Kalverda Jouke Annema Peter Bonta \\ Department of Pulmonology, Amsterdam University Medical Centers, University of Amsterdam, Amsterdam, The \\ Netherlands
}

\section{Keywords}

Optical coherence tomography - Confocal laser endomicroscopy - Obstructive lung disease .

Bronchoscopy $\cdot$ Lung cancer $\cdot$ Interstitial lung disease

\begin{abstract}
Diagnosing and monitoring pulmonary diseases is highly dependent on imaging, physiological function tests and tissue sampling. Optical coherence tomography (OCT) and confocal laser endomicroscopy (CLE) are novel imaging techniques with near-microscopic resolution that can be easily and safely combined with conventional bronchoscopy. Disease-related pulmonary anatomical compartments can be visualized, real time, using these techniques. In obstructive lung diseases, airway wall layers and related structural remodelling can be identified and quantified. In malignant lung disease, normal and malignant areas of the central airways, lung parenchyma, lymph nodes and pleura can be discriminated. A growing number of interstitial lung diseases (ILDs) have been visualized using OCT or CLE. Several ILD-associated structural changes can be imaged: fibrosis, cellular infiltration, bronchi(ol)ectasis, cysts and microscopic honeycombing. Although not yet implemented in clinical practice, OCT and CLE have the potential to improve detection and monitoring pulmonary diseases and can contrib-
\end{abstract}

ute in unravelling the pathophysiology of disease and mechanism of action of novel treatments. Indeed, assessment of the airway wall layers with OCT might be helpful when evaluating treatments targeting airway remodelling. By visualizing individual malignant cells, CLE has the potential as a real-time lung cancer detection tool. In the future, both techniques could be combined with laser-enhanced fluorescent-labelled tracer detection. This review discusses the value of OCT and CLE in pulmonary medicine by summarizing the current evidence and elaborating on future perspectives.

(C) 2019 The Author(s) Published by S. Karger AG, Basel

\section{Introduction}

Diagnosing pulmonary diseases is highly dependent on imaging techniques such as high-resolution computed tomography of the chest (HRCT) or minimal invasive

A.G. and K.A.K. contributed equally to this work.

From the Thematic Review Series: "Emerging Techniques in the World of Respiratory Imaging"

Series Editors: Lowie E.G.W. Vanfleteren and Dirk-Jan Slebos

\section{(C) 2019 The Author(s)}

Published by S. Karger AG, Basel

Karger

Open access

This article is licensed under the Creative Commons AttributionNonCommercial-NoDerivatives 4.0 International License (CC BYNC-ND) (http://www.karger.com/Services/OpenAccessLicense). Usage and distribution for commercial purposes as well as any distribution of modified material requires written permission.
Peter Bonta, $\mathrm{MD}, \mathrm{PhD}$

Department of Pulmonology, Amsterdam University Medical Centers University of Amsterdam, F5-144, Meibergdreef 9

NL-1105 AZ Amsterdam (The Netherlands)

E-Mail p.i.bonta@amsterdamumc.nl 


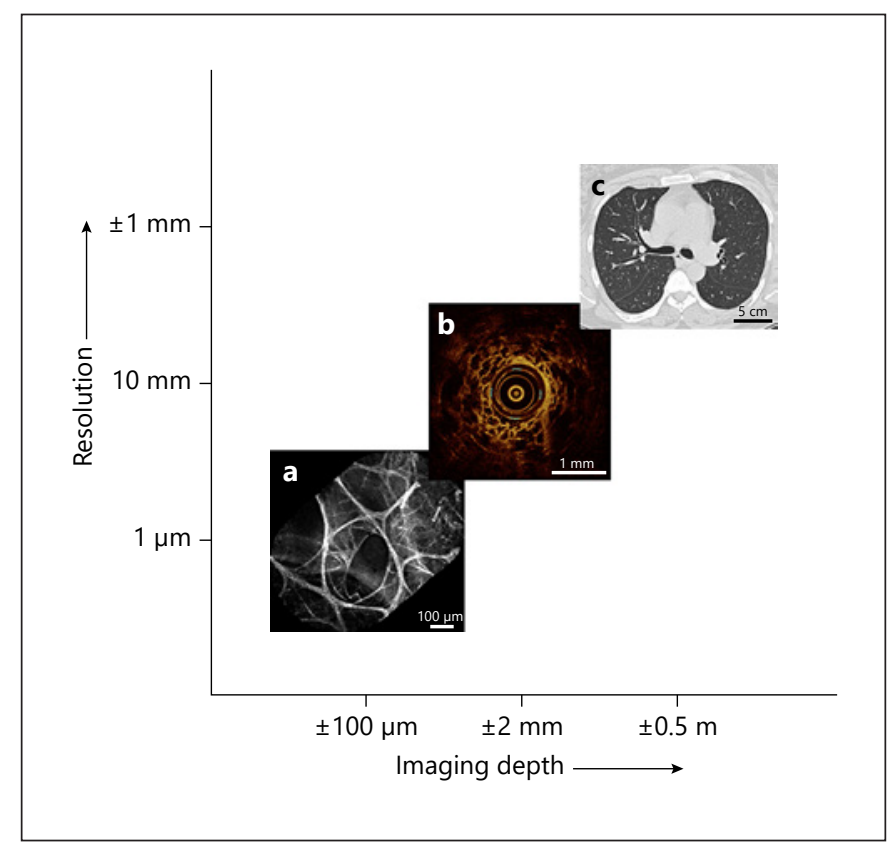

Fig. 1. Imaging techniques applied to the alveolar compartment with their corresponding resolution and imaging depth. a CLE. b OCT. c HRCT of the chest.

procedures like bronchoscopy for tissue sampling. HRCT imaging contributes to the diagnosis of many pulmonary diseases; however, spatial resolution is limited and patients are subjected to ionizing radiation. Endobronchial sampling, such as mucosal and parenchymal biopsies and needle aspiration, is associated with a complication risk, subject to sampling error and provides only information on one specific sampling site.

To diagnose and understand the pathophysiology of pulmonary diseases and monitor treatments, higher imaging resolution beyond HRCT on a histological/cellular level might be helpful. Optical coherence tomography (OCT) and confocal laser endomicroscopy (CLE) are 2 novel imaging techniques that can fill this gap between invasive and selective tissue sampling and the limited resolution of HRCT. All these techniques are complementary: from a large overview of the lung (HRCT) to nearmicroscopic imaging (CLE; Fig. 1). In this review, we discuss the value of bronchoscopic OCT and CLE in pulmonary diseases by summarizing OCT and CLEbased imaging studies using the anatomical compartments related to obstructive lung diseases, pulmonary malignancies and interstitial lung diseases (ILD; Fig. 2, Table 1). Furthermore, potential future clinical applications of these imaging techniques in pulmonary disease management are discussed (Table 1). The applicability of
OCT in pulmonary vascular diseases has been described in a previously published review and is discussed less extensively [1].

\section{Technical Background}

\section{Optical Coherence Tomography}

OCT is an imaging technique using near-infrared light to generate high-resolution images of tissue structures with a resolution of $\pm 10-15 \mu \mathrm{m}$ and depth of $2-3 \mathrm{~mm}$ (Fig. 1) [2,3]. The conceptual idea of OCT is comparable to ultrasound, but instead of using the reflection of acoustic waves, OCT uses the scattering of near-infrared light to generate images. An advantage of OCT over (radial) endobronchial ultrasound is that light waves do not need a transducing medium or direct contact with the tissue and therefore has excellent properties to be used in air filled anatomical compartments such as the airways. In short, in OCT, an optical beam generates near-infrared light and focuses on the tissue. The difference in time of light backscattering in structures is measured and compared with a reference beam by using principles of optical interferometry. This enables the OCT system to generate 2D cross-sectional images (Fig. 2, 3). Subsequently, consecutive $2 \mathrm{D}$ images generated by pullbacks can be reconstructed to 3D structures. Although many applications in medicine are explored, at first, OCT was clinically implemented in ophthalmology to image the retina [4-6]. Furthermore, OCT is nowadays applied to assess stenosis and stent apposition in coronary arteries in interventional cardiology [7-10]. For pulmonary purposes, OCT has not yet been clinically implemented. However in the last decade, studies have shown that OCT is feasible, safe and has added value in pulmonary medicine for a broad field of indications (Table 1). The studies in this review investigating the use of OCT in pulmonary medicine have used either company build OCT probes (St. Jude Medical Inc., Abbott, IL, USA; Pentax Corp., Tokyo, Japan; light-CTTM scanner, LLTech, France; LightLab Imaging Inc., Westford, USA; Niris Imaging System, Imalux Corp., Cleveland, OH, USA) or custom build devices. OCT images of the airways and/or alveolar compartment are captured during bronchoscopy (Fig. 3a-c). The OCT catheter is inserted through the working channel of a bronchoscope and advanced until the region of interest is reached. Subsequently by manual or automated pullback, the OCT catheter generates sequential cross-sectional images of segments of the anatomical compartment of interest including the airways, lung parenchyma and pulmonary ar- 


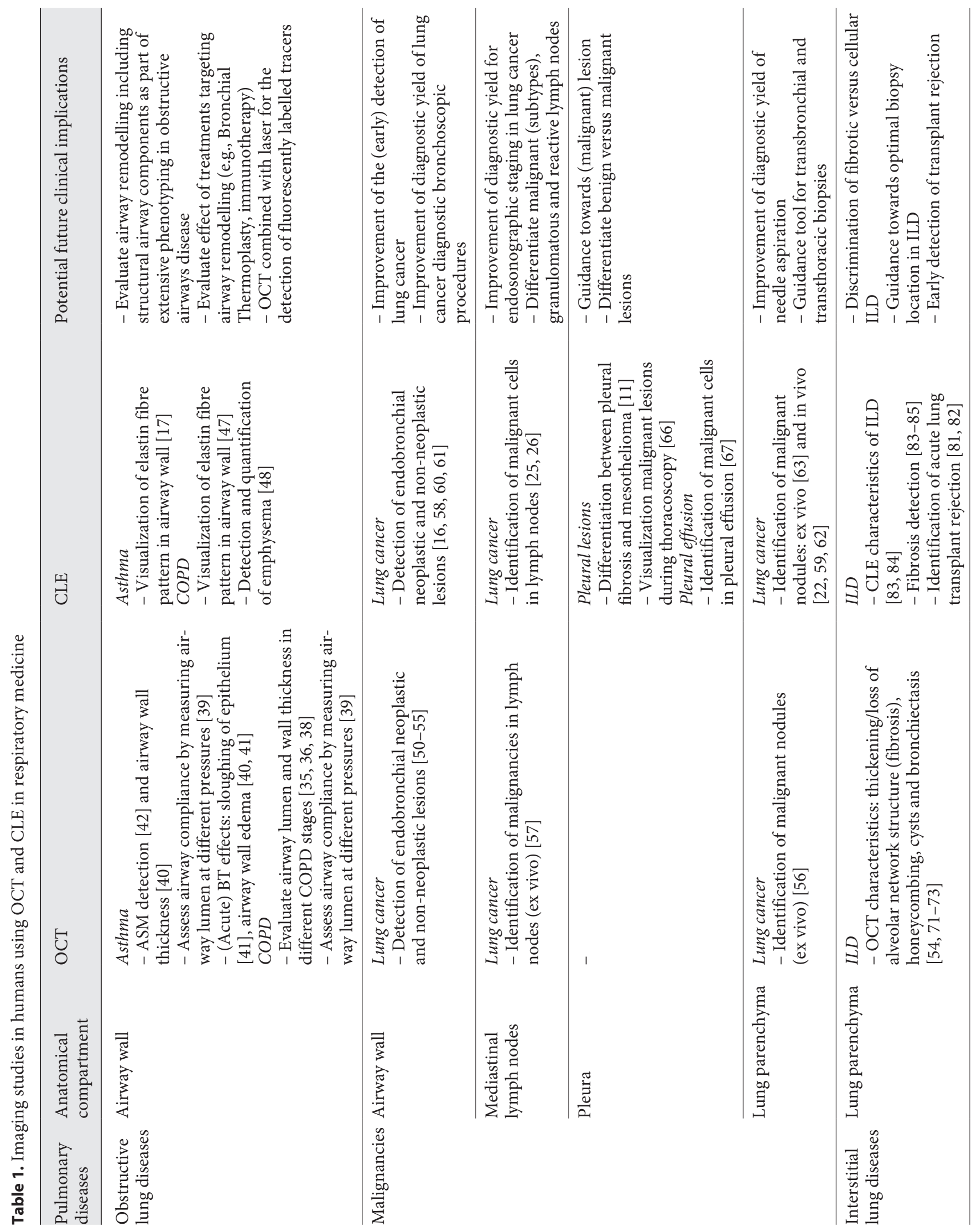




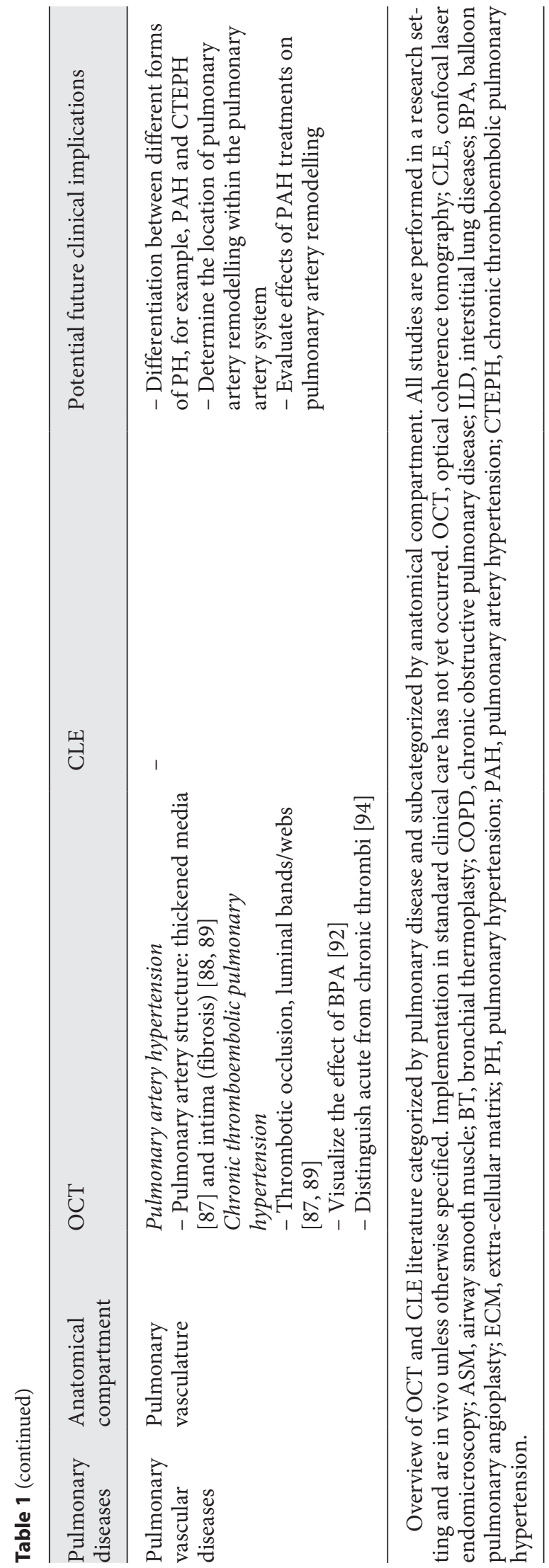

OCT and CLE Imaging in Pulmonary Diseases teries (Fig. 3, Table 1). This review summarizes the advances that OCT made in improving diagnosis and management of obstructive lung diseases, malignancies and ILDs.

\section{Confocal Laser Endomicroscopy}

CLE is an imaging technique compatible with bronchoscopy, thoracoscopy and transthoracic needle-based interventions [11], which provides real-time images of the airways, alveoli, lung tumours, pleura and lymph nodes with a resolution up to $3.5 \mu \mathrm{m}$, with a maximum depth of $70 \mu \mathrm{m}$ and a maximum field of view of $600 \mu \mathrm{m}$ (Fig. 1, 2). A fibre-optic probe is advanced through the working channel of a bronchoscope, thoracoscope or needle and directed to the area of interest where it illuminates tissue with laser light (most commonly used $488 \mathrm{~nm}$ ). Reflected light is redirected back through a pinhole. Only light that is exactly in focus will pass through the pinhole, resulting in high-resolution images. Moving the laser beam vertically or horizontally enables reconstruction of 3D images by special software. In literature, CLE is also referred to as fibred confocal fluorescence microscopy, confocal microendoscopy or alveoloscopy. In this paper, we use the term CLE for this imaging technique. When the CLE probe is combined with a needle (CLE probe advanced through a hollow needle), the term "needle-based CLE" (nCLE) is used. "Probe-based CLE" (pCLE) refers to the technique where the CLE probe is advanced to the tissue, thereby directly omitting the need of a needle (Fig. 4).

Most evidence for the application of CLE in clinical practice is available in gastro-intestinal diseases, for instance, in the detection of neoplasia in the oesophagus [12, 13] and pancreatic cysts [14]. In non-malignant diseases like ulcerative colitis, CLE has been shown to be superior to any other imaging modality to assess mucosal healing [15].

First in vivo, in humans, reports on pCLE in the respiratory tract date back to 2007. Earliest studies showed feasibility of imaging of the airway wall and demonstrated that the images obtained by pCLE rely on the presence of elastin fibres, which is auto-fluorescent at $488 \mathrm{~nm}$ laser light $[16,17]$. As elastin forms the backbone of structural components in the alveolar compartment including alveolar septae and microvessels [18-20] and the pleura, these can be visualized, real time and in vivo, using pCLE. Additionally, cellular components including inflammatory cells such as alveolar macrophages can be imaged based on auto-fluorescence as well [21].

Currently, in pulmonary diseases, one CLE system is commercially available (Cellvizio Endomicroscopy System, Mauna Kea Technologies, Paris, France). For pCLE, 


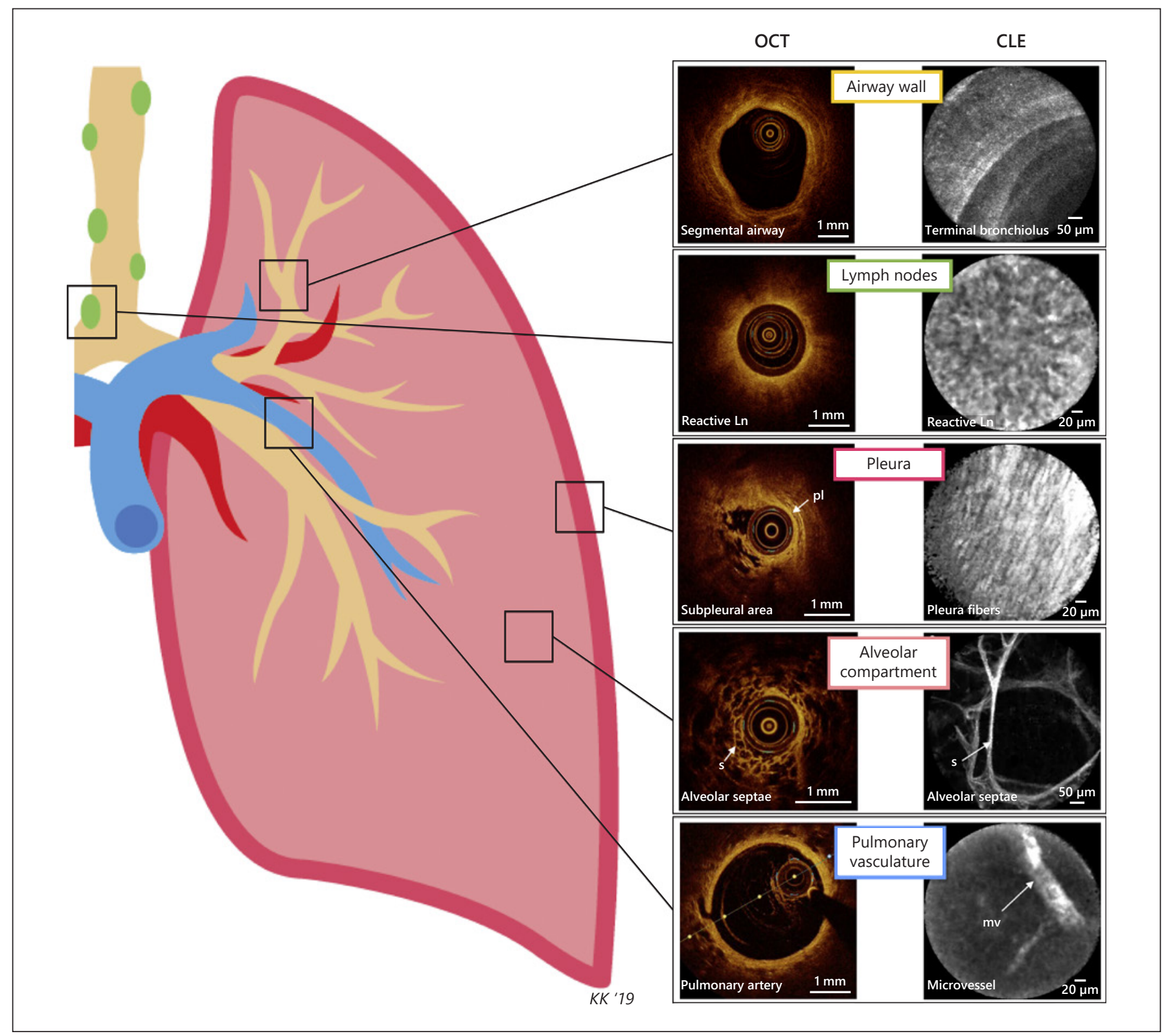

Fig. 2. Overview of the pulmonary anatomical compartments with corresponding OCT and CLE images. Airway wall: OCT, crosssectional view of airway wall in segmental airway; CLE, pCLE image showing a typical helical ring-like pattern of terminal bronchiole. Lymph nodes: OCT, image in a reactive lymph node; CLE, nCLE image showing abundant lymphocytes in a reactive lymph node. Pleura: OCT, image of subpleural area, $\mathrm{pl}$ is indicated by the white arrow; CLE, lamellar organized elastin fibres in the $\mathrm{pl}$ as seen

a miniprobe compatible with $1.9 \mathrm{~mm}$ working channel $\left(\right.$ Alveoflex ${ }^{\mathrm{TM}}$ ) can be used to visualize all segments of the bronchial tree and lung parenchyma (Fig. 2). However, when reaching for the upper lobes (apical and posterior with pCLE. Alveolar compartment: OCT, cross-sectional view of alveolar compartment with network of alveolar s; CLE, pCLE image of alveolar compartment showing alveolar septae with rectangular airspaces. Pulmonary vasculature: OCT, cross-sectional view from pulmonary artery; CLE, nCLE image of an mv in a lymph node. OCT, optical coherence tomography; CLE, confocal laser endomicroscopy; Ln, lymph node; pl, pleura; s, septa; mv, microvessel. 


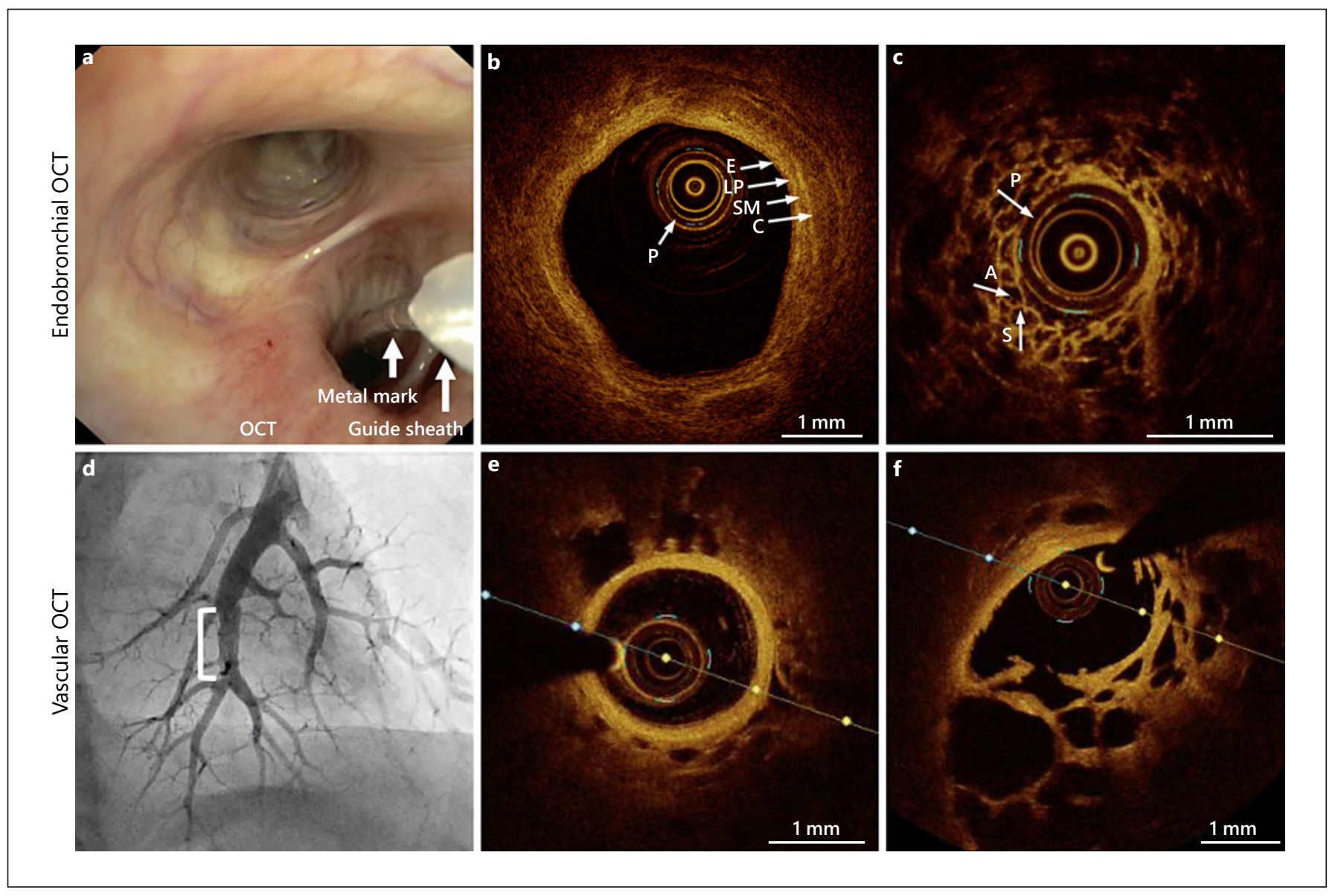

Fig. 3. OCT imaging procedures of the airway wall and alveolar compartment (endobronchial OCT; a-c) and pulmonary artery (vascular OCT, $\mathbf{d}-\mathbf{f})$. a Bronchoscopic view of an OCT imaging procedure showing the guide sheath and the OCT catheter positioned in the right lower lobe. The metal mark guides the distance of $5.4 \mathrm{~cm}$ to the distal tip of the OCT catheter. $\mathbf{b}$ OCT image of a normal segmental airway wall showing the airway wall layer identification. c OCT image of the alveolar compartment showing normal alveoli and septae. d Angiography of the left lower lobe pulmonary artery with a stenosis in a chronic thromboembolic pulmonary hypertension (CTEPH) patient (white bracket). e OCT image of a normal proximal pulmonary artery. $\mathbf{f}$ OCT image of a pulmonary artery with webs/bands in a CTEPH patient. (Images provided by H.J. Bogaard, $\mathrm{MD}, \mathrm{PhD} ; \mathrm{N}$. van Royen, $\mathrm{MD}, \mathrm{PhD}$ and $\mathrm{M}$. Beijk, MD, PhD). OCT, optical coherence tomography; $\mathrm{P}$, probe; A, alveolar space; $\mathrm{S}$, septae; E, epithelium; LP, lamina propria; SM, submucosa; C, cartilage. shown no advantage using fluorescein to visualize epithelial cells. Indeed, it has been reported that the visualization of alveoli is reduced using fluorescein because of a foamlike substance that appears $[23,24]$.

For imaging of lung masses and/or mediastinal lymph nodes, the needle-based CLE technique can be used. For this purpose, the thinnest confocal probe (AQ-flex ${ }^{\mathrm{TM}}$ ) is advanced through a 19 -Gauge needle. Unlike using pCLE in the respiratory tract, intravenous fluorescein-dinatrium should be administrated. Fluorescein enables the visualization of individual cells by enhancing fluorescence of the stromal background. Single cells are not stained by fluorescein, which results in a negative-like image where the individual

OCT and CLE Imaging in Pulmonary Diseases cells are seen as dark dots on a bright background (Fig. 4f). With nCLE, different anatomical structures in lymph nodes can be identified. The capsula with auto fluorescent elastin fibres can be distinguished from the cortex in which the lymphoid cells can be identified (Fig. 4), as well as the lymphoid follicles, which appear as large dark discs $[25,26]$.

\section{Obstructive Lung Diseases}

\section{Optical Coherence Tomography}

Obstructive lung diseases such as asthma and chronic obstructive pulmonary disease (COPD) are characterized 

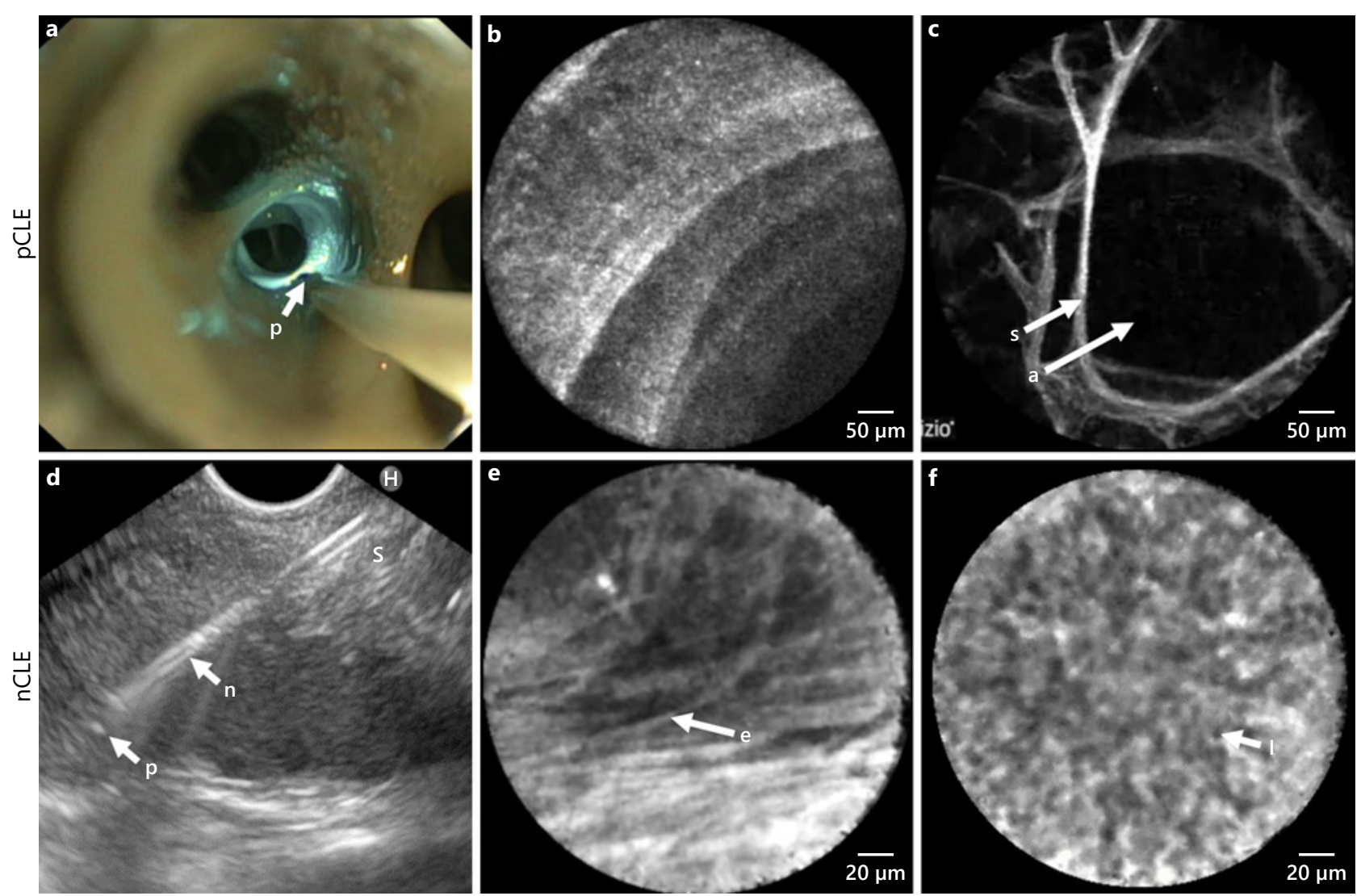

Fig. 4. pCLE imaging procedures in vivo with corresponding images of the normal alveolar and airway wall compartment $(\mathbf{a}-\mathbf{c})$; nCLE imaging in vivo with corresponding images of reactive lymph node capsula and cortex (d-f). a pCLE with the probe (p) positioned in the central airways of the right lower lobe on its way to be advanced to the alveolar compartment. $488 \mathrm{~nm}$ laser light reflecting at the airway wall (blue). $\mathbf{b}$ pCLE image of the distal airway wall showing a helical ring-like pattern of the terminal bronchiole.

by airway remodelling, which includes structural changes and thickening of the airway wall [27-29]. Next to inflammation, airway remodelling is a key pathophysiological characteristic in asthma, which is associated with disease severity. Therefore, it is of importance to develop accurate tools to assess airway wall remodelling [30]. By showing a high correlation with histology for both identification (Fig. 3c) and quantification of airway wall layers in both animal studies [31] and human airways [32-34], OCT is considered a promising technique to assess airway remodelling in obstructive lung diseases.

The value of OCT is further substantiated by several studies that have correlated OCT imaging of the airway wall to HRCT and pulmonary function parameters. Coxson et c pCLE image of the alveolar compartment showing air-filled alveoli (a) and alveolar septae (s). d nCLE during an EUS procedure for staging of lung cancer, with the probe (p) extending $2 \mathrm{~mm}$ distal to the tip of the needle (n). e nCLE image showing elastin fibres (e) of the capsula of a lymph node. $\mathbf{f}$ nCLE image showing lymphocytes (1) in a reactive lymph node Wijmans et al. [85]. pCLE, probe based confocal laser endomicroscopy; S, septae; A, alveolar space; nCLE, needle based confocal laser endomicroscopy.

al. [35] have compared HRCT with OCT imaging in a cohort of 44 current and former smokers and showed a strong correlation for airway wall thickness. In addition, in this study, forced expiratory volume in 1 second $\left(\mathrm{FEV}_{1}\right)$ was measured and correlated to airway wall thickness of fifthgeneration airways measured by both HRCT and OCT, with OCT showing the strongest correlation. This correlation between $\mathrm{FEV}_{1}$ and airways was confirmed in another study in which several stages of COPD patients were included and a high correlation between OCT measured airway wall dimensions and $\mathrm{FEV}_{1}$-based staging was found [36]. In allergic asthma patients, $\mathrm{FEV}_{1} / \mathrm{FVC}$ correlated with OCT measured epithelial thickness and mucosal buckling, a potential method to assess bronchoconstriction [37]. Also 


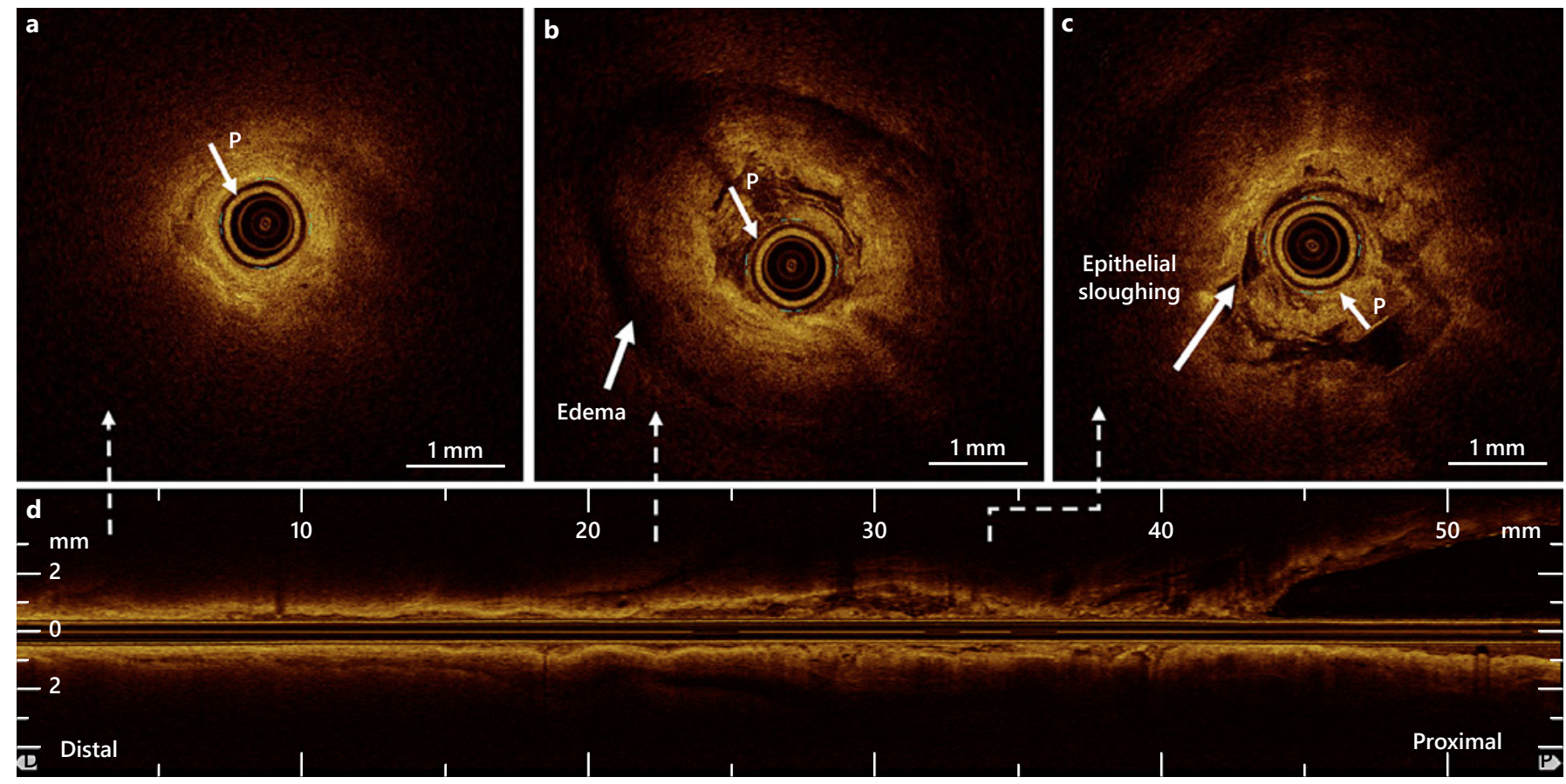

Fig. 5. OCT images of the anterior segment (LB3) of the left upper lobe directly after ronchial thermoplasty (BT) treatment. a Normal, non-directly-BT-treated distal airway area. b BT-treated airway area with peribronchial oedema. c BT-treated airway area showing epithelial sloughing. d Corresponding reconstructed pullback of the airway (540 2D images, total length of $5.4 \mathrm{~cm}$; Goorsenberg et al. [41]). P, probe.

with impulse oscillometry, a lung function test that uses sound waves to assess the respiratory resistance found that a correlation existed between the airway wall areas of small airways (seventh to ninth generation) assessed with OCT and respiratory resistance in heavy smokers and COPD patients [38]. Additionally, OCT can be used to assess elastic properties of the airway wall when combined with airway pressure increasing methods [39].

Next to assessing airway remodelling in patients with obstructive lung diseases, OCT might contribute in unravelling the mechanism of action of new treatment techniques and the evaluation of treatment response. In severe asthma, OCT was used in a pilot study of 2 severe asthma patients to assess the effect of bronchial thermoplasty (BT) on the airway wall up to 2 years after treatment [40]. Although the 2 included patients in this study showed similar clinical asthma symptoms and spirometry measurements, only 1 patient responded to BT. OCT was used to explore differences between these 2 patients and revealed a thickened, probably inflamed, epithelium in the non-responder patient, while the responder had a thickened airway wall without signs of inflammation. Also, after BT a difference was described: in the respond- er the total airway wall thickness declined, while in the non-responder, the thickness remained the same. These results suggested that OCT might have a potential role in identifying characteristics at baseline for optimal patient selection for BT.

In severe asthma, OCT has also been used to assess the acute effects of BT on the airway wall and identified acute patterns within the airway wall including epithelial sloughing and oedema (Fig. 5). Interestingly, acute BT effects extended to the distal smaller non-BT-treated airways and this suggested that BT treatment might also impact the smaller airways in severe asthmatic patients [41].

Although different airway wall layers are detectable with OCT, measuring the layers manually is time consuming and it remains difficult to identify the different structures and components within these layers such as extracellular matrix (ECM) proteins (e.g., collagen) or airway smooth muscle (ASM). By adding a birefringent platform to the OCT system, Adams et al. [42] automatically identified and quantified ASM fibres in 3 asthma patients and 3 healthy controls showing a significant difference in the thickness of ASM fibres between these 2 groups. 


\section{Confocal Laser Endomicroscopy}

Visualization of the airway wall using pCLE relies on elastin fibres in subepithelial ECM. In the bronchi, 5 different patterns can be identified, depending on the depth of the probe in the bronchial tree [16]. Ranging from dense unidirectional elastin fibres, with an occasional bronchial gland opening in proximal main bronchi, to cross-sectional fibres and loose, web-like fibres in distal, smaller airways, the distal terminal bronchiole shows a typical ring like helical pattern (Fig. 4). In patients with asthma, elastin fibres have been described to be decreased or fragmented [43]. However, in a study that focused on pCLE imaging in asthma patients and healthy controls, it was described that a dense lamellar pattern was associated with lower $\mathrm{FEV}_{1}$ [17]. In COPD, to our knowledge, only a single study imaged the airway walls with CLE. Of the different subepithelial elastin patterns, COPD patients were described to have more loose arrangements of elastin fibres, instead of a lamellar or mixed pattern of fibres, as compared to non-COPD smokers and healthy volunteers. Possibly indicating destruction of elastin fibres in the ECM of the airway wall of COPD patients, which is in line with a previous histological study by Black et al. [44].

In the alveolar compartment, animal studies have shown a correlation between pulmonary emphysema and enlarged airspaces with thinner capillaries and a loss of capillary density $[45,46]$. This correlation was reproduced using pCLE in COPD patients in vivo, thus without the need for biopsy. Furthermore, COPD patients were shown to have decreased auto fluorescence intensity of alveolar septae when compared to healthy volunteers, potentially indicating destruction of these, elastin containing, alveolar septae $[24,47,48]$. Although pCLE shows specific findings in patients with COPD, the additional value of pCLE over standard chest CT and pulmonary function tests is yet to be established.

\section{Malignancies}

\section{Optical Coherence Tomography}

The detection of lung cancer tissue for diagnosis and staging purposes, but also for margin assessment in lung cancer surgery, is highly important in the management of pulmonary oncology. Several groups have investigated the use of OCT in other oncology specialties, mainly in dermatology, urology and gastroenterology [49].

The involvement of pulmonary malignancies in different anatomical compartments can be imaged with OCT including central airway endobronchial malignancies, lung parenchymal pulmonary masses or nodules and metastases in lymph nodes.

For the identification of endobronchial tumours, promising results have been published both in vivo [5052] and ex vivo [52-55]. In these endobronchial tumours, one study identified different characteristics for 3 subtypes of cancer: squamous cell carcinomas, adenocarcinomas and poorly differentiated carcinomas [55]. Three reviewers were trained to identify these criteria in a cohort of 82 ex vivo tumour samples that showed an average accuracy of $82.6 \%$ (range $73.7-94.7 \%$ ). To the best of our knowledge, there are no studies published investigating the value of OCT in assessing the margin of the tumourresected tissue.

In pulmonary masses, nodules and lymph node metastases, a potential use of OCT is needle-based OCT imaging in the setting of trans-bronchial needle aspiration. One research group conducted a study in pulmonary nodules showing high sensitivity and specificity (both $>95 \%$ ) for ex vivo differentiation between pulmonary nodules and healthy parenchymal tissue [56]. The same research group investigated the use of OCT for the identification of pulmonary lymph node metastases. Needlebased OCT was performed in 26 ex vivo lymph nodes, both healthy and metastatic disease [57]. The characteristics of metastatic disease were distinct from those of the lymph nodes without cancer and even had features connected with the subtype of the tumour. Both applications of needle-based OCT in pulmonary nodules and lymph nodes have not been validated in vivo yet.

\section{Confocal Laser Endomicroscopy}

Several studies have shown that pCLE has the ability to identify the abnormal area in endobronchial $[16,58-$ 61] and parenchymal-located malignancies (both primary lung cancer and metastatic) $[58,62,63]$. Using pCLE to image endobronchial lesions, Filner et al. [61] showed the ability to differentiate between normal versus neoplastic lesions and normal versus non-neoplastic lesions. In a study performed in 112 patients with a peripheral pulmonary nodule, pCLE was able to detect the abnormal area in $92 \%$ [64]. Additionally, Sorokina et al. [63] showed the presence of a specific pattern of alveolar dystelectasis, oedema and influx of macrophages to be present in malignant nodules in 18 lobectomy specimens. Additionally, pCLE histopathology confirmed distinctive features of adenocarcinoma, squamous cell carcinoma and small cell carcinoma. However, in a study performed by Seth et al. [64], 91 patients with peripheral lung nodule were imaged with pCLE, and although in $92 \%$ the abnormal area was 

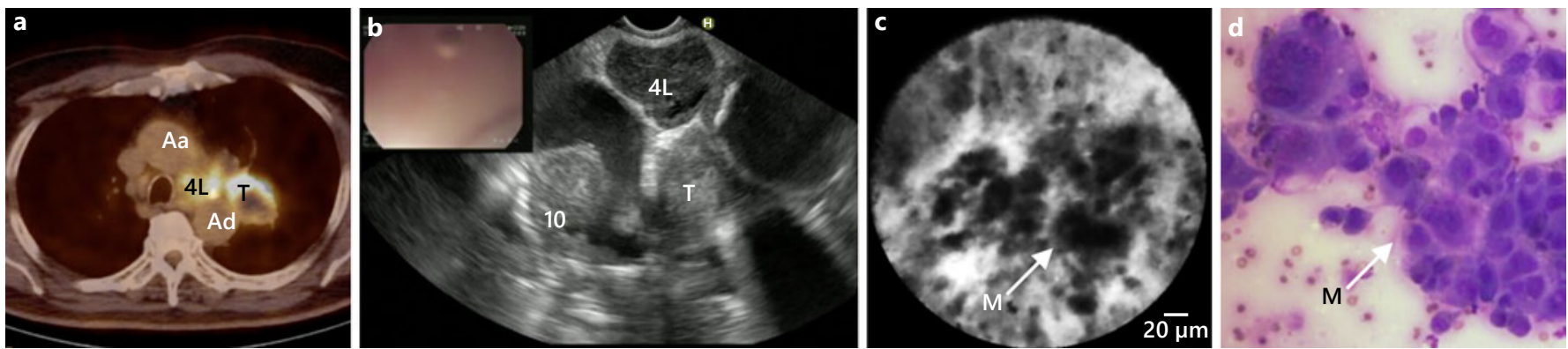

Fig. 6. Endosonography guided nCLE of a mediastinal lymph node metastasis of a tumour in the left upper lobe. a PET-CT scan showing fludeoxyglucose-avid lymph node station $4 \mathrm{~L}$, and the primary lung tumour (T). b EUS image showing an enlarged lymph nodes at station $4 \mathrm{~L}$. c Real-time nCLE image of lymph node station $4 \mathrm{~L}$ showing large pleomorphic cells and dark clumps recognized as malignant cells $(\mathrm{M})$. $\mathbf{d}$ Fine needle aspirate showing malignant cells of squamous cell carcinoma (Wijmans et al. [26]). 10, lymph node station $10 \mathrm{~L}$ (left); Aa, ascending aorta; Ad, descending aorta. identified, pCLE was not able to discriminate benign from malignant lesions. It is thought that this is due to the difficulty of staining epithelial cells of the bronchial mucosa $[16,59,63,64]$. Unlike the mucosa of the gastrointestinal tract, fluorescein does not penetrate into the epithelial layer of the bronchi $[23,24]$. Topical administrated acriflavine has shown high sensitivity and specificity to visualize malignant cells in endobronchial located tumours; however, its use is under discussion because of its potential carcinogenic properties [60].

An approach where the nodule is punctured by a needle combined with the CLE probe might resolve the problem of bronchial epithelial staining. In 2016, Wijmans et al. [65] presented a case of non-small cell lung cancer in which the primary tumour was imaged with nCLE in combination with intravenous fluorescein. Where all the previous mentioned studies for peripheral pulmonary nodules have used pCLE, Wijmans et al. [65] demonstrated in this study a case in which the primary tumour was visualized with nCLE combined with endosonography. Dark, large aggregates of cells imaged with nCLE were compatible with the malignant cells of adenocarcinoma Thereafter, a study was performed using nCLE in both centrally located primary pulmonary tumours $(n=6)$ and metastasis suspected lymph nodes $(n=21)$. Three characteristics were developed to predict malignancy: enlarged pleomorphic cells, dark clumps and directional streaming. These criteria were prospectively validated to determine malignancy of the tumours or lymph nodes with high diagnostic accuracy of $90 \%$ [26] (Fig. 6).

In pleural lesions, both pCLE and nCLE have been used to detect malignant cells. Bonhomme et al. [66] reported 3 cases with pleura imaging using pCLE. Three different images of the pleura were presented: normal pleura, pleural metastasized non-small cell lung cancer and a case of mesothelioma. pCLE of the pleura showed clear capability to differentiate normal pleura from malignant pleura in these cases. Shortly thereafter, a larger study was undertaken using both pCLE and nCLE to distinguish malignant mesothelioma from areas of pleural fibrosis. Characteristics of different pleural lesions were identified and prospectively validated in 105 pleural biopsies from 15 patients with moderate inter-observer agreement [11]. When it comes to malignant pleural effusion, one ex vivo study found high sensitivity and specificity for pleural malignancy using pCLE in pleural effusion [67].

\section{ILDs and Other Parenchymal Lung Diseases}

\section{Optical Coherence Tomography}

OCT has predominantly been used to assess abnormalities in the airway due to both obstructive airway diseases and (endobronchial) malignancies. However, recently, the use of OCT for the assessment of the alveolar compartment has been investigated [68-70]. Especially in ILDs the added value of high-resolution, near-microscopic imaging next to HRCT can be envisioned. In 2013, Hariri et al. [54] compared the histology of human lung specimens with optical frequency domain imaging in 4 patients ex vivo. Characteristics of fibrosis were identified in these OCT images. More recently, the first in vivo in human results of OCT in diagnosis of idiopathic pulmonary fibrosis has been published [71-73]. These results showed that OCT was able to identify microscopic honeycombing with alveolar OCT, while radiological honeycombing was not visible on HRCT [71]. Furthermore, characteristics for fi- 

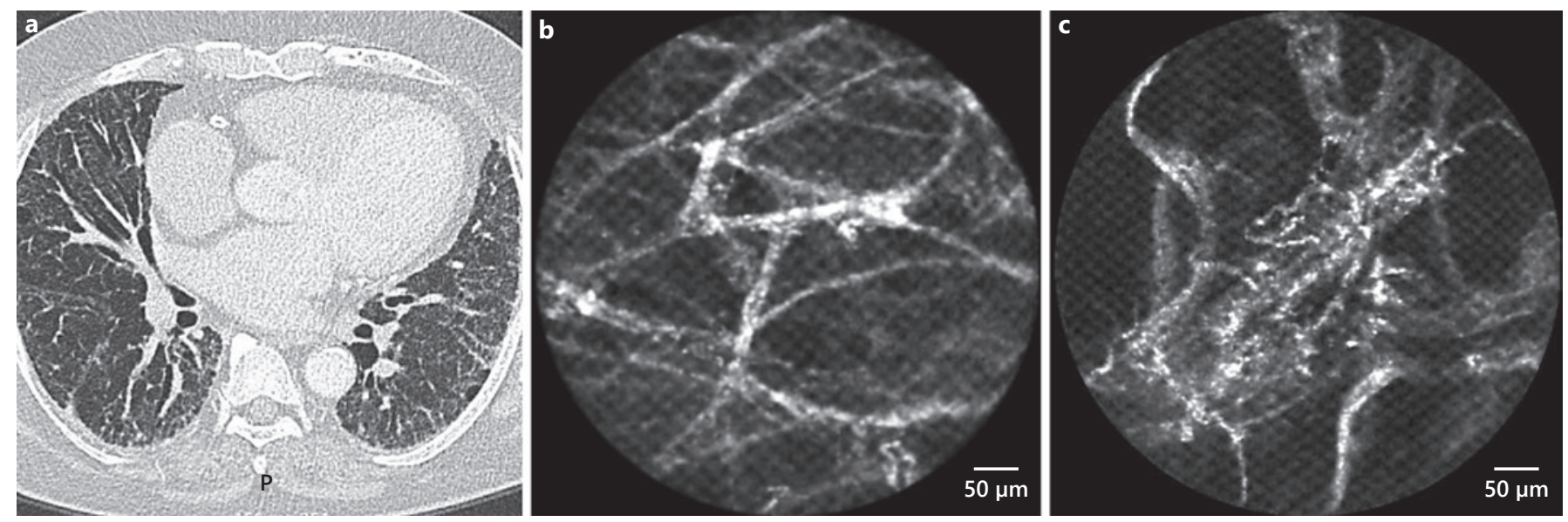

Fig. 7. pCLE images of the alveolar compartment in a patient with a fibrotic NSIP. a HRCT image showing diffuse reticulation and bronchi(ol)ectasis. $\mathbf{b}$ pCLE image showing an increased density of alveolar elastin fibre intact network. c pCLE image showing an increased density of thickened alveolar elastin fibre network with loss of normal architecture Wijmans et al. [85]. P, probe.

brotic ILDs such as thickening of alveolar septae and loss of alveolar structure, microscopic honeycombing, cysts and bronchi(ol)ectasis were identified with OCT [71-73].

\section{Confocal Laser Endomicroscopy}

Since ILD is a disease located in the alveolar compartment, CLE has been used to visualize ILD in vivo. Normal alveolar compartment images show thin alveolar septae in a round, helical or looped shape depending on the angle of penetration of the alveolar unit (Fig. 2, 4). Microvessels can be visualized and are typically thicker than the alveolar septae, and may have branches. In smoking individuals, highly fluorescent macrophages are visible throughout the alveoli, which has a positive correlation with the number of cigarettes used [21]. Also, the fluorescent intensity of alveolar structures varies: older individuals tend to have stronger fluorescent signals of alveolar elastin fibres $[21,24]$.

The first report of CLE in ILD was a case of pulmonary alveolar proteinosis, in which highly fluorescent globular structures were identified in vivo, compatible with globular lipoproteinaceous material in broncho-alveolar lavage. Similar findings were described in a case series of 6 patients with pulmonary alveolar proteinosis [74]. Later, case reports of amiodarone induced ILD, pulmonary alveolar microlithiasis, invasive aspergillosis, pneumocystis jiroveci pneumonia, lymphangioleiomyomatosis and metastatic pulmonary calcification were published [75-80].

In addition to the above, CLE has also been studied for the surveillance of acute cellular rejection (ACR) in lung transplant recipients. Two studies have focused on the use of pCLE in these patients and found that specific characteristics are associated with ACR. Yserbyt et al. [81] showed in 2014 the correlation between ACR and an increase in auto fluorescent alveolar cells. This finding was confirmed by Keller et al. [82] in 2019, with the addition of the perivascular distribution of the cells. Perivascular cellularity was significantly correlated with ACR.

Several studies have been performed to identify specific characteristics of pCLE images in ILD. Meng et al. [83] identified 6 different patterns to discriminate chronic fibrosing ILD from other ILDs. Salaün et al. [84] identified 9 specific CLE characteristics using data from 80 individuals (59 ILD patients, 21 healthy individuals). Based on these characteristics they were able to discriminate normal from diseased lung, and found that certain ILDs were associated with a cellular CLE pattern (presence of fluorescent bronchial and alveolar cells), while others were associated with a fibrotic CLE pattern (small alveolar mouths, disorganized dense elastin fibre network with thickened septae). They showed good reproducibility of inter-observer interpretation. In another observational study in 14 ILD patients pCLE was able to detect normal and abnormal parenchymal areas, and to discriminate mild from severe fibrosis (Fig. 7). Additionally the pleura and the adjacent subpleural alveolar space could be identified [85].

Based on the studies reviewed above, it seems plausible that pCLE can differentiate cellular ILDs from fibrotic ILDs; however, whether CLE can differentiate between 
specific subsets of ILDs remains to be established. The potential of CLE to identify these different compartments, along with an added value to characterize ILD, paves the way to use CLE as a guidance tool for endoscopic (cryo-)lung biopsies.

\section{Pulmonary Vascular Diseases}

\section{Optical Coherence Tomography}

The use of OCT in pulmonary vascular diseases has been described thoroughly in previously published reviews by our group and others $[1,86]$. In short, OCT has been investigated in characterizing pulmonary artery wall remodelling in pulmonary arterial hypertension [87-89]. Pulmonary artery wall thickness has been reported to correlate to hemodynamic parameters $[90,91]$. In chronic thromboembolic pulmonary hypertension, OCT was able to assess thrombotic occlusion and luminal webs and/or bands [87, 89] (Fig. 3f) and has been reported to guide balloon sizing and to evaluate the effect of balloon pulmonary angioplasty treatment $[92,93]$. Additionally, one study investigated the use of OCT in diagnosing peripheral pulmonary artery thrombus as compared to selective pulmonary angiography in 12 patients [94]. In this study, OCT found significantly more thrombi in the distal segments of peripheral pulmonary arteries than selective pulmonary angiography. Moreover, OCT was able to differentiate between acute "red" and chronic "white" thrombi.

\section{Confocal Laser Endomicroscopy}

To the best of our knowledge, no studies have been published regarding the use of CLE in pulmonary vascular diseases.

\section{Future Perspectives}

In summary, in pulmonary medicine, OCT and CLE are promising high-resolution, real-time, in vivo imaging techniques to visualize important disease associated anatomical compartments of the respiratory tract. However, unlike in ophthalmology and cardiology, OCT and CLE have not found their implementation into standard clinical care yet.

In our opinion, the use of both CLE and OCT techniques has high potential to add to guidance and/or improvement in diagnostic yield driven by its near-microscopic resolution and real-time properties. For instance, the development of a CLE or OCT integrated cytological

OCT and CLE Imaging in Pulmonary Diseases needle (so called smart needle) to guide the biopsy site and provide real-time feedback for the detection of lung cancer and pleura mesothelioma [11].

In addition, since advanced OCT and CLE have shown the potential of in situ cytological analysis in malignancysuspected lymph nodes, it seems reasonable that these techniques also have the capability of detecting granulomas in, for instance, sarcoidosis.

The scope of novel imaging techniques in endoscopy may be broadened in the near future by implementing the use of fluorescently labelled tracers. In this field of imaging, optical techniques are combined with laser to detect fluorescently labelled components. In oncology, fluorescently labelled antibody detection can further boost tumour identification for cancer diagnosis, staging and assessment of tumour margins. For instance, fluorescently labelled anti-CD47 was used to detect bladder cancer [95]. Both fluorescently labelled labetuzumab and erlotinib have been used to assess colorectal cancer and EGFR-mutated lung tumours, respectively, in xenografted mouse models $[96,97]$. Furthermore, to evaluate the effect of novel treatments, pCLE might be of value as was demonstrated by a study in which apoptotic cells were visualized after the administration of erlotinib in EGFRmutated tumours in animal models [98]. In severe asthma patients, it can be envisioned that molecular labelling of monoclonal antibodies used for immunotherapy can help to visualize cellular targets and biodistribution of these antibodies with the ultimate goal to improve patient selection for these expensive therapies.

In the field of infectious diseases, efforts are made to directly visualize the presence of pathogens. So far, both in- and ex vivo studies have been published to visualize aspergillus [99-101] and staphylococcus aureus [102] in animal models using CLE.

Currently, analyzing OCT and CLE images is elaborative and this makes it a time-consuming process. The development of automated software is essential for the implementation of these techniques. Automated segmentation based on intensity analyses or deep learning techniques might prove very helpful in image analyses and will be a necessity for broader clinical application. Improvements are being made, such as automated quantification [42] and automated mucus segmentation [37, 103]. Also, research is focused on improving the techniques, for instance, by using polarization sensitive OCT, which shows not only the structural layers of the airway wall but also the arrangement of the tissue [104]. This makes it possible to distinguish several structures in the airways such as structural airway components (e.g., ECM/ 
ASM). Additionally, the resolution of OCT imaging might be improved by using a nano-optic endoscope: a conventional OCT system with a metalens integrated in the design [105]. Potentially these techniques can be used to assess treatment effects on airway wall structures involved in airway wall remodelling, without the need for taking a biopsy. Other factors limiting the implementation of these techniques in clinical practice are the lack of larger validation trials, costs and availability of OCT and CLE systems. Currently, pulmonary OCT and CLE have been used only in research trials in expert centres with expertise in interventional bronchoscopy with relatively small amounts of patients included.

\section{Conclusion}

Both OCT and CLE are complementary, high-resolution imaging techniques that have shown to be feasible and safe to use in a variety pulmonary diseases. Both techniques have considerable potential to improve diagnostics and monitoring of pulmonary diseases and their treatments; however, larger in vivo validation studies and automated software are needed before these techniques can be implemented in clinical practice.

\section{Acknowledgements}

We would like to thank J. de Boer, PhD, F. Ferold, and J. Willemse for providing polarization sensitive OCT images of an asthma patient; H.J. Bogaard, $\mathrm{MD}, \mathrm{PhD}, \mathrm{N}$. van Rooijen, $\mathrm{MD}, \mathrm{PhD}$, and M. Beijk, MD, PhD for providing OCT images of the pulmonary vasculature and L. Wijmans for providing CLE images.

\section{Statement of Ethics}

The authors have no ethical conflicts to disclose.

\section{Disclosure Statement}

The department of pulmonology received material support from St Jude Medical Inc., St. Paul, MN, USA/Abbott, Illinois and an unrestricted research grant from Mauna Kea Technologies, Paris, France.

\section{Funding Sources}

None.

\section{Author Contributions}

A.G., K.A.K., P.B. and J.A. contributed to the concept and design of this review. A.G. and K.A.K. both contributed equally to data interpretation, writing the manuscript and preparing figures. P.B. and J.A. supervised the project and reviewed the manuscript. All authors approved the final version.

\section{References}

1 Wijmans L, d'Hooghe JN, Bonta PI, Annema JT. Optical coherence tomography and confocal laser endomicroscopy in pulmonary diseases. Curr Opin Pulm Med. 2017 May;23(3): 275-83.

2 Huang D, Swanson EA, Lin CP, Schuman JS, Stinson WG, Chang W, et al. Optical coherence tomography. Science. 1991 Nov; 254(5035):1178-81.

3 Tearney GJ, Brezinski ME, Bouma BE, Boppart SA, Pitris C, Southern JF, et al. In vivo endoscopic optical biopsy with optical coherence tomography. Science. 1997 Jun; 276(5321):2037-9.

4 Fercher AF, Hitzenberger CK, Drexler W, Kamp G, Sattmann H. In vivo optical coherence tomography. Am J Ophthalmol. 1993 Jul;116(1):113-4.

5 Swanson EA, Izatt JA, Hee MR, Huang D, Lin $\mathrm{CP}$, Schuman JS, et al. In vivo retinal imaging by optical coherence tomography. Opt Lett. 1993 Nov; 18(21):1864-6.
6 Koustenis A Jr, Harris A, Gross J, Januleviciene I, Shah A, Siesky B. Optical coherence tomography angiography: an overview of the technology and an assessment of applications for clinical research. Br J Ophthalmol. 2017 Jan;101(1):16-20.

7 IJsselmuiden AJ, Zwaan EM, Oemrawsingh RM, Bom MJ, Dankers FJ, de Boer MJ, et al. Appropriate use criteria for optical coherence tomography guidance in percutaneous coronary interventions : recommendations of the working group of interventional cardiology of the Netherlands Society of Cardiology. Neth Heart J. 2018 Oct;26(10):473-83.

8 Sotomi Y, Tateishi H, Suwannasom P, Dijkstra J, Eggermont J, Liu S, et al. Quantitative assessment of the stent/scaffold strut embedment analysis by optical coherence tomography. Int J Cardiovasc Imaging. 2016 Jun; 32(6):871-83

9 Bezerra HG, Costa MA, Guagliumi G, Rollins AM, Simon DI. Intracoronary optical coher- ence tomography: a comprehensive review clinical and research applications. JACC Cardiovasc Interv. 2009 Nov;2(11):1035-46.

10 Brezinski ME, Tearney GJ, Boppart SA, Swanson EA, Southern JF, Fujimoto JG. Optical biopsy with optical coherence tomography: feasibility for surgical diagnostics. J Surg Res. 1997 Jul;71(1):32-40.

11 Wijmans L, Baas P, Sieburgh TE, de Bruin DM, Ghuijs PM, van de Vijver MJ, et al. Confocal Laser Endomicroscopy as a Guidance Tool for Pleural Biopsies in Malignant Pleural Mesothelioma. Chest. 2019, Epub ahead of print.

12 Sharma P, Meining AR, Coron E, Lightdale CJ, Wolfsen HC, Bansal A, et al. Real-time increased detection of neoplastic tissue in Barrett's esophagus with probe-based confocal laser endomicroscopy: final results of an international multicenter, prospective, randomized, controlled trial. Gastrointest Endosc. 2011 Sep;74(3):465-72. 
13 Shah T, Lippman R, Kohli D, Mutha P, Solomon S, Zfass A. Accuracy of probe-based confocal laser endomicroscopy (pCLE) compared to random biopsies during endoscopic surveillance of Barrett's esophagus. Endosc Int Open. 2018 Apr;6(4):E414-20.

14 Napoleon B, Palazzo M, Lemaistre AI, Caillol F, Palazzo L, Aubert A, et al. Needlebased confocal laser endomicroscopy of pancreatic cystic lesions: a prospective multicenter validation study in patients with definite diagnosis. Endoscopy. 2019 Sep; 51(9):825-35.

15 Macé V, Ahluwalia A, Coron E, Le Rhun M, Boureille A, Bossard C, et al. Confocal laser endomicroscopy: a new gold standard for the assessment of mucosal healing in ulcerative colitis. J Gastroenterol Hepatol. 2015 Mar;30 Suppl 1:85-92.

16 Thiberville L, Moreno-Swirc S, Vercauteren T, Peltier E, Cavé C, Bourg Heckly G. In vivo imaging of the bronchial wall microstructure using fibered confocal fluorescence microscopy. Am J Respir Crit Care Med. 2007 Jan; 175(1):22-31.

17 Yick CY, von der Thüsen JH, Bel EH, Sterk PJ, Kunst PW. In vivo imaging of the airway wall in asthma: fibered confocal fluorescence microscopy in relation to histology and lung function. Respir Res. 2011 Jun; 12(1):85.

18 Mercer RR, Crapo JD. Spatial distribution of collagen and elastin fibers in the lungs. J Appl Physiol (1985). 1990 Aug;69(2):756-65.

19 Gonçalves CA, Figueiredo MH, Bairos VA. Three-dimensional organization of the elastic fibres in the rat lung. Anat Rec. 1995 Sep; 243(1):63-70.

20 Toshima M, Ohtani Y, Ohtani O. Three-dimensional architecture of elastin and collagen fiber networks in the human and rat lung. Arch Histol Cytol. 2004 Mar;67(1):31-40.

21 Thiberville L, Salaün M, Lachkar S, Dominique S, Moreno-Swirc S, Vever-Bizet C, et al. Human in vivo fluorescence microimaging of the alveolar ducts and sacs during bronchoscopy. Eur Respir J. 2009 May;33(5): 974-85.

22 Hassan T, Thiberville L, Hermant C, Lachkar S, Piton N, Guisier F, et al. Assessing the feasibility of confocal laser endomicroscopy in solitary pulmonary nodules for different part of the lungs, using either 0.6 or $1.4 \mathrm{~mm}$ probes. PLoS One.2017 Dec;12(12):e0189846.

23 Fuchs FS, Zirlik S, Hildner K, Frieser M, Ganslmayer M, Schwarz S et al. Fluoresceinaided confocal laser endomicroscopy of the lung. Respiration. 2011;81(1):32-8.

24 Newton RC, Kemp SV, Yang GZ, Elson DS, Darzi A, Shah PL. Imaging parenchymal lung diseases with confocal endomicroscopy. Respir Med. 2012 Jan;106(1):127-37.

25 Benias PC, D'Souza LS, Papafragkakis H, Kim J, Harshan M, Theise ND, et al. Needle-based confocal endomicroscopy for evaluation of malignant lymph nodes - a feasibility study. Endoscopy. 2016 Oct;48(10):923-8.
26 Wijmans L, Yared J, de Bruin DM, Meijer SL, Baas P, Bonta PI, et al. Needle-based confocal laser endomicroscopy for real-time diagnosing and staging of lung cancer. Eur Respir J. 2019 Jun;53(6):1-9.

27 Jeffery PK. Remodeling in asthma and chronic obstructive lung disease. Am J Respir Crit Care Med. 2001 Nov; 164(10 Pt 2 supplement_2):S28-38.

28 James AL, Wenzel S. Clinical relevance of airway remodelling in airway diseases. Eur Respir J. 2007 Jul;30(1):134-55.

29 Patel BD, Coxson HO, Pillai SG, Agustí AG, Calverley PM, Donner CF, et al.; International COPD Genetics Network. Airway wall thickening and emphysema show independent familial aggregation in chronic obstructive pulmonary disease. Am J Respir Crit Care Med. 2008 Sep;178(5):500-5.

30 Benayoun L, Druilhe A, Dombret MC, Aubier M, Pretolani M. Airway structural alterations selectively associated with severe asthma. Am J Respir Crit Care Med. 2003 May;167(10): $1360-8$.

31 Lee AM, Kirby M, Ohtani K, Candido T, Shalansky R, MacAulay C, et al. Validation of airway wall measurements by optical coherence tomography in porcine airways. PLoS One. 2014 Jun;9(6):e100145.

32 Chen Y, Ding M, Guan WJ, Wang W, Luo WZ, Zhong $\mathrm{CH}$, et al. Validation of human small airway measurements using endobronchial optical coherence tomography. Respir Med. 2015 Nov;109(11):1446-53.

33 d'Hooghe JN, Goorsenberg AW, de Bruin DM, Roelofs JJ, Annema JT, Bonta PI. Optical coherence tomography for identification and quantification of human airway wall layers. PLoS One. 2017 Oct;12(10):e0184145.

34 Kirby M, Ohtani K, Nickens T, Lisbona RM, Lee AM, Shaipanich T, et al. Reproducibility of optical coherence tomography airway imaging. Biomed Opt Express. 2015 Oct;6(11): 4365-77.

35 Coxson HO, Quiney B, Sin DD, Xing L, McWilliams AM, Mayo JR, et al. Airway wall thickness assessed using computed tomography and optical coherence tomography. Am J Respir Crit Care Med. 2008 Jun;177(11):1201-6.

36 Ding M, Chen Y, Guan WJ, Zhong CH, Jiang M, Luo WZ, et al. Measuring Airway Remodeling in Patients With Different COPD Staging Using Endobronchial Optical Coherence Tomography. Chest. 2016 Dec;150(6): 1281-90.

37 Adams DC, Miller AJ, Applegate MB, Cho JL, Hamilos DL, Chee A, et al. Quantitative assessment of airway remodelling and response to allergen in asthma. Respirology. 2019, Epub ahead of print.

38 Su ZQ, Guan WJ, Li SY, Ding M, Chen Y, Jiang $M$, et al. Significances of spirometry and impulse oscillometry for detecting small airway disorders assessed with endobronchial optical coherence tomography in COPD. Int J Chron Obstruct Pulmon Dis. 2018 Oct;13: 3031-44.
39 Williamson JP, McLaughlin RA, Noffsinger WJ, James AL, Baker VA, Curatolo A, et al. Elastic properties of the central airways in obstructive lung diseases measured using anatomical optical coherence tomography. Am J Respir Crit Care Med. 2011 Mar;183(5):6129.

40 Kirby M, Ohtani K, Lopez Lisbona RM, Lee AM, Zhang W, Lane P, et al. Bronchial thermoplasty in asthma: 2-year follow-up using optical coherence tomography. Eur Respir J. 2015 Sep;46(3):859-62.

41 Goorsenberg AWM, d'Hooghe JNS, de Bruin DM, van den Berk IAH, Annema JT, Bonta PI. Bronchial Thermoplasty-Induced Acute Airway Effects Assessed with Optical Coherence Tomography in Severe Asthma. Respiration. 2018;96(6):564-70.

42 Adams DC, Hariri LP, Miller AJ, Wang Y, Cho JL, Villiger M, et al. Birefringence microscopy platform for assessing airway smooth muscle structure and function in vivo. Sci Transl Med. 2016 Oct;8(359): 359ra131.

43 Bousquet J, Lacoste JY, Chanez P, Vic P, Godard P, Michel FB. Bronchial elastic fibers in normal subjects and asthmatic patients. Am J Respir Crit Care Med. 1996 May;153(5): 1648-54.

44 Black PN, Ching PS, Beaumont B, Ranasinghe S, Taylor G, Merrilees MJ. Changes in elastic fibres in the small airways and alveoli in COPD. Eur Respir J. 2008 May;31(5):9981004.

45 Yamato H, Sun JP, Churg A, Wright JL. Cigarette smoke-induced emphysema in guinea pigs is associated with diffusely decreased capillary density and capillary narrowing. Lab Invest. 1996 Aug;75(2):211-9.

46 Schraufnagel DE, Schmid A. Capillary structure in elastase-induced emphysema. Am J Pathol. 1988 Jan;130(1):126-35.

47 Cosío BG, Shafiek H, Fiorentino F, Gómez C, López M, Rios A, et al. Structure-function relationship in COPD revisited: an in vivo microscopy view. Thorax. 2014 Aug;69(8):72430.

48 Yserbyt J, Dooms C, Janssens W, Verleden GM. Endoscopic advanced imaging of the respiratory tract: exploring probe-based confocal laser endomicroscopy in emphysema. Thorax. 2018 Feb;73(2):188-90.

49 van Manen L, Dijkstra J, Boccara C, Benoit E, Vahrmeijer AL, Gora MJ, et al. The clinical usefulness of optical coherence tomography during cancer interventions. J Cancer Res Clin Oncol. 2018 Oct;144(10):1967-90.

50 Lam S, Standish B, Baldwin C, McWilliams A, leRiche J, Gazdar A et al. In vivo optical coherence tomography imaging of preinvasive bronchial lesions. Clin Cancer Res. 2008 Apr; 14(7):2006-11.

51 Michel RG, Kinasewitz GT, Fung KM, Keddissi JI. Optical coherence tomography as an adjunct to flexible bronchoscopy in the diagnosis of lung cancer: a pilot study. Chest. 2010 Oct;138(4):984-8. 
52 Tsuboi M, Hayashi A, Ikeda N, Honda H, Kato Y, Ichinose S, et al. Optical coherence tomography in the diagnosis of bronchial lesions. Lung Cancer. 2005 Sep;49(3):38794.

53 Jain M, Narula N, Salamoon B, Shevchuk MM, Aggarwal A, Altorki N, et al. Full-field optical coherence tomography for the analysis of fresh unstained human lobectomy specimens. J Pathol Inform. 2013 Sep;4(1): 26.

54 Hariri LP, Applegate MB, Mino-Kenudson M, Mark EJ, Medoff BD, Luster AD, et al. Volumetric optical frequency domain imaging of pulmonary pathology with precise correlation to histopathology. Chest. 2013 Jan; 143(1):64-74.

55 Hariri LP, Mino-Kenudson M, Lanuti M, Miller AJ, Mark EJ, Suter MJ. Diagnosing lung carcinomas with optical coherence tomography. Ann Am Thorac Soc. 2015 Feb;12(2): 193-201.

56 Hariri LP, Mino-Kenudson M, Applegate MB, Mark EJ, Tearney GJ, Lanuti M, et al. Toward the guidance of transbronchial biopsy: identifying pulmonary nodules with optical coherence tomography. Chest. 2013 Oct; 144(4):1261-8

57 Shostak E, Hariri LP, Cheng GZ, Adams DC, Suter MJ. Needle-based Optical Coherence Tomography to Guide Transbronchial Lymph Node Biopsy. J Bronchology Interv Pulmonol. 2018 Jul;25(3):189-97.

58 Wellikoff AS, Holladay RC, Downie GH, Chaudoir CS, Brandi L, Turbat-Herrera EA. Comparison of in vivo probe-based confocal laser endomicroscopy with histopathology in lung cancer: A move toward optical biopsy. Respirology. 2015 Aug;20(6):967-74.

59 Shah PL, Kemp SV, Newton RC, Elson DS, Nicholson AG, Yang GZ. Clinical Correlation between Real-Time Endocytoscopy, Confocal Endomicroscopy, and Histopathology in the Central Airways. Respiration. 2017;93(1):517.

60 Fuchs FS, Zirlik S, Hildner K, Schubert J, Vieth M, Neurath MF. Confocal laser endomicroscopy for diagnosing lung cancer in vivo. Eur Respir J. 2013 Jun;41(6):1401-8.

61 Filner JJ, Bonura EJ, Lau ST, Abounasr KK, Naidich D, Morice RC, et al. Bronchoscopic fibered confocal fluorescence microscopy image characteristics and pathologic correlations. J Bronchology Interv Pulmonol. 2011 Jan;18(1):23-30.

62 Hassan T, Piton N, Lachkar S, Salaün M, Thiberville L. A Novel Method for In Vivo Imaging of Solitary Lung Nodules Using Navigational Bronchoscopy and Confocal Laser Microendoscopy. Lung. 2015 Oct; 193(5):773-8.

63 Sorokina A, Danilevskaya O, Averyanov A, Zabozlaev F, Sazonov D, Yarmus L, et al. Comparative study of ex vivo probe-based confocal laser endomicroscopy and light microscopy in lung cancer diagnostics. Respirology. 2014 Aug;19(6):907-13.
64 Seth S, Akram AR, McCool P, Westerfeld J, Wilson D, McLaughlin S, et al. Assessing the utility of autofluorescence-based pulmonary optical endomicroscopy to predict the malignant potential of solitary pulmonary nodules in humans. Sci Rep. 2016 Aug;6(1): 31372.

65 Wijmans L, de Bruin DM, Meijer SL, Annema JT. Real-Time Optical Biopsy of Lung Cancer. Am J Respir Crit Care Med. 2016 Oct; 194(8):e10-1.

66 Bonhomme O, Duysinx B, Heinen V, Detrembleur N, Corhay JL, Louis R. First report of probe based confocal laser endomicroscopy during medical thoracoscopy. Respir Med. 2019 Feb;147:72-5

67 Zirlik S, Hildner K, Rieker RJ, Vieth M, Neurath MF, Fuchs FS. Confocal Laser Endomicroscopy for Diagnosing Malignant Pleural Effusions. Med Sci Monit. 2018 Aug;24:543747.

68 Quirk BC, McLaughlin RA, Curatolo A, Kirk RW, Noble PB, Sampson DD. In situ imaging of lung alveoli with an optical coherence tomography needle probe. J Biomed Opt. 2011 Mar;16(3):036009.

69 McLaughlin RA, Yang X, Quirk BC, Lorenser D, Kirk RW, Noble PB, et al. Static and dynamic imaging of alveoli using optical coherence tomography needle probes. J Appl Physiol (1985). 2012 Sep;113(6):967-74

70 Meissner S, Knels L, Krueger A, Koch T, Koch E. Simultaneous three-dimensional optical coherence tomography and intravital microscopy for imaging subpleural pulmonary alveoli in isolated rabbit lungs. J Biomed Opt. 2009 Sep-Oct; 14(5):054020.

71 Hariri LP, Adams DC, Wain JC, Lanuti M, Muniappan A, Sharma A, et al. Endobronchial Optical Coherence Tomography for LowRisk Microscopic Assessment and Diagnosis of Idiopathic Pulmonary Fibrosis In Vivo. Am J Respir Crit Care Med. 2018 Apr;197(7): 949-52.

72 Wijmans L, de Bruin DM, Bonta PI, Jonkers RE, Poletti V, Annema JT. OCT, a Valuable Novel Tool for Assessing the Alveolar Compartment in ILD? Am J Respir Crit Care Med. 2017;197(9):1231-2

73 Wijmans L dBD, Jonkers R, Roelofs J, van den Berk I, Bonta P, Annema J. Visualizing the alveolar compartment in ILD patients by optical coherence tomography [abstract]. Presented at the European Respiratory Society Congress. September 10, 2017, Milan, Italy. Abstract 5061.

74 Danilevskaya O, Averyanov A, Lesnyak V, Chernyaev A, Sorokina A. Confocal laser endomicroscopy for diagnosis and monitoring of pulmonary alveolar proteinosis. J Bronchology Interv Pulmonol. 2015 Jan;22(1):3340.

75 Salaün M, Roussel F, Bourg-Heckly G, VeverBizet C, Dominique S, Genevois A, et al. In vivo probe-based confocal laser endomicroscopy in amiodarone-related pneumonia. Eur Respir J. 2013 Dec;42(6):1646-58.
76 Yserbyt J, Alamé T, Dooms C, Ninane V. Pulmonary alveolar microlithiasis and probebased confocal laser endomicroscopy. J Bronchology Interv Pulmonol. 2013 Apr;20(2): 159-63.

77 Yserbyt J, Dooms C, Ninane V, Decramer M, Verleden G. Perspectives using probe-based confocal laser endomicroscopy of the respiratory tract. Swiss Med Wkly. 2013 Mar; 143:w13764.

78 Danilevskaya O, Averyanov A, Klimko N, Lesnyak V, Sorokina A, Sazonov D, et al. The case of diagnostics of invasive pulmonary aspergillosis by in vivo probe-based confocal laser endomicroscopy of central and distal airways. Med Mycol Case Rep. 2014 Jul;5:359.

79 Shafiek H, Fiorentino F, Cosio BG, Kersul A, Thiberville L, Gomez C et al. Usefulness of Bronchoscopic Probe-Based Confocal Laser Endomicroscopy in the Diagnosis of Pneumocystis jirovecii Pneumonia. Respiration. 2016;92(1):40-7.

80 Vasilev I, Mamenko I, Tabanakova I, Vikulova I, Shevel V, Ushkov A, et al. Probe-based Confocal Laser Endomicroscopy in Metastatic Pulmonary Calcification. J Bronchology Interv Pulmonol. 2018 Jan;25(1):60-2.

81 Yserbyt J, Dooms C, Decramer M, Verleden GM. Acute lung allograft rejection: diagnostic role of probe-based confocal laser endomicroscopy of the respiratory tract. J Heart Lung Transplant. 2014 May;33(5):492-8.

82 Keller CA, Khoor A, Arenberg DA, Smith MA, Islam SU. Diagnosis of Acute Cellular Rejection Using Probe-based Confocal Laser Endomicroscopy in Lung Transplant Recipients: A Prospective, Multicenter Trial. Transplantation. 2019 Feb;103(2):428-34.

83 Meng P, Tan GL, Low SY, Takano A, Ng YL, Anantham D. Fibred confocal fluorescence microscopy in the diagnosis of interstitial lung diseases. J Thorac Dis. 2016 Dec;8(12): 3505-14.

84 Salaün M, Guisier F, Dominique S, Genevois A, Jounieaux V, Bergot E, et al. In vivo probebased confocal laser endomicroscopy in chronic interstitial lung diseases: specific descriptors and correlation with chest CT. Respirology. 2019 Aug;24(8):783-91.

85 Wijmans L, Bonta PI, Rocha-Pinto R, de Bruin DM, Brinkman P, Jonkers RE, et al. Confocal Laser Endomicroscopy as a Guidance Tool for Transbronchial Lung Cryobiopsies in Interstitial Lung Disorder. Respiration. 2019; 97(3):259-63.

86 Jorge E, Baptista R, Calisto J, Faria H, Monteiro P, Pan M, et al. Optical coherence tomography of the pulmonary arteries: A systematic review. J Cardiol. 2016 Jan;67(1):614.

87 Tatebe S, Fukumoto Y, Sugimura K, Nakano M, Miyamichi S, Satoh K et al. Optical coherence tomography as a novel diagnostic tool for distal type chronic thromboembolic pulmonary hypertension. Circ J. 2010 Aug;74(8): $1742-4$. 
88 Domingo E, Grignola JC, Aguilar R, Montero MA, Arredondo C, Vázquez M, et al. In vivo assessment of pulmonary arterial wall fibrosis by intravascular optical coherence tomography in pulmonary arterial hypertension: a new prognostic marker of adverse clinical follow-up. Open Respir Med J. 2013 Apr;7(1): 26-32.

89 Jiang X, Peng FH, Liu QQ, Zhao QH, He J, Jiang R, et al. Optical coherence tomography for hypertensive pulmonary vasculature. Int $J$ Cardiol. 2016 Nov;222:494-8.

90 Homma Y, Hayabuchi Y, Ono A, Kagami S. Pulmonary Artery Wall Thickness Assessed by Optical Coherence Tomography Correlates With Pulmonary Hemodynamics in Children With Congenital Heart Disease. Circ J. 2018 Aug 24;82(9):2350-7.

91 Dai Z, Fukumoto Y, Tatebe S, Sugimura K, Miura Y, Nochioka K, et al. OCT imaging for the management of pulmonary hypertension. JACC Cardiovasc Imaging. 2014 Aug;7(8):843-5.

92 Sugimura K, Fukumoto Y, Satoh K, Nochioka K, Miura Y, Aoki T et al. Percutaneous transluminal pulmonary angioplasty markedly improves pulmonary hemodynamics and longterm prognosis in patients with chronic thromboembolic pulmonary hypertension. Circ J. 2012;76(2):485-8.

93 Roik M, Wretowski D, Łabyk A, Kostrubiec M Rowiński O, Pruszczyk P. Optical coherence tomography of inoperable chronic thromboembolic pulmonary hypertension treated with refined balloon pulmonary angioplasty. Pol Arch Med Wewn. 2014;124(12):742-3.
94 Hong C, Luo FQ, Liu CL, Zhong NS, Li JY, Wang W. Clinical study of optical coherence tomography in the diagnosis of peripheral pulmonary artery thrombus. Thromb Res. 2018 Jan;161:52-9.

95 Pan Y, Volkmer JP, Mach KE, Rouse RV, Liu JJ, Sahoo D, et al. Endoscopic molecular imaging of human bladder cancer using a CD47 antibody. Sci Transl Med. 2014 Oct; 6(260):260ra148.

96 Feroldi F, Verlaan M, Knaus H, Davidoiu V, Vugts DJ, van Dongen GA, et al. High resolution combined molecular and structural optical imaging of colorectal cancer in a xenograft mouse model. Biomed Opt Express. 2018 Nov;9(12):6186-204

97 Patout M, Guisier F, Brune X, Bohn P, Romieu A, Sarafan-Vasseur N, et al. Real-time molecular optical micro-imaging of EGFR mutations using a fluorescent erlotinib based tracer. BMC Pulm Med. 2019 Jan; 19(1):3.

98 Guisier F, Bohn P, Patout M, Piton N, Farah $\mathrm{I}$, Vera $\mathrm{P}$, et al. In- and ex-vivo molecular imaging of apoptosis to assess sensitivity of non-small cell lung cancer to EGFR inhibitors using probe-based confocal laser endomicroscopy. PLoS One. 2017 Jul; 12(7):e0180576.

99 Morisse H, Heyman L, Salaün M, Favennec L, Picquenot JM, Bohn P, et al. In vivo and in situ imaging of experimental invasive pulmonary aspergillosis using fibered confocal fluorescence microscopy. Med Mycol. 2012 May;50(4):386-95.
100 Morisse H, Heyman L, Salaün M, Favennec $\mathrm{L}$, Picquenot JM, Bohn $\mathrm{P}$, et al. In vivo molecular microimaging of pulmonary aspergillosis. Med Mycol. 2013 May;51(4):35260

101 Vanherp L, Poelmans J, Hillen A, Govaerts $\mathrm{K}$, Belderbos S, Buelens T, et al. Bronchoscopic fibered confocal fluorescence microscopy for longitudinal in vivo assessment of pulmonary fungal infections in free-breathing mice. Sci Rep. 2018 Feb;8(1): 3009.

102 Mills B, Akram AR, Scholefield E, Bradley M, Dhaliwal K. Optical Screening of Novel Bacteria-specific Probes on Ex Vivo Human Lung Tissue by Confocal Laser Endomicroscopy. J Vis Exp. 2017 Nov; 129.

103 Adams DC, Pahlevaninezhad H, Szabari MV, Cho JL, Hamilos DL, Kesimer M, et al. Automated segmentation and quantification of airway mucus with endobronchial optical coherence tomography. Biomed Opt Express. 2017 Sep;8(10):4729-41.

104 Feroldi F, Willemse J, Davidoiu V, Gräfe MG, van Iperen DJ, Goorsenberg AW, et al. In vivo multifunctional optical coherence tomography at the periphery of the lungs. Biomed Opt Express. 2019 May;10(6):307091.

105 Pahlevaninezhad H, Khorasaninejad M, Huang YW, Shi Z, Hariri LP, Adams DC, et al. Nano-optic endoscope for high-resolution optical coherence tomography in vivo. Nat Photonics. 2018 Sep;12(9):5407. 